\title{
Origins of Internal Regioselectivity in Copper-Catalyzed Borylation of Terminal Alkynes
}

\author{
Takumi Tsushima, ${ }^{1}$ Hideya Tanaka, ${ }^{1}$ Kazuki Nakanishi, ${ }^{1}$ Masaaki Nakamoto, ${ }^{1}$ and Hiroto Yoshida ${ }^{1 *}$ \\ ${ }^{1}$ Graduate School of Advanced Science and Engineering, Hiroshima University, Higashi-Hiroshima 739-8526, Japan \\ *Correspondence: yhiroto@hiroshima-u.ac.jp
}

\section{SUMMARY}

Installation of a boron functionality into a more substituted carbon of terminal alkynes has been a challenging issue in chemical synthesis, since inherently Lewis acidic boron moieties, in principle, favor their attachment to a terminal carbon. Herein, we report on the highly internal-selective borylation of terminal alkynes under copper catalysis, wherein diminishment of boron-Lewis acidity and ligandderived steric bulk around a copper center are the key to the success. In particular, the use of an anthranilamide-substituted boron moiety $[B(a a m)]$ is of high synthetic significance, because its properly diminished Lewis acidity enabled the internal regioselectivity and the Suzuki-Miyaura cross-coupling activity to be compatibly achieved. This method provided direct and universal approach to variously substituted branched alkenylboron compounds, regardless of electronic and steric properties of a substituent on terminal alkynes.

\section{INTRODUCTION}

In view of the established synthetic significance of organoboron compounds, ${ }^{1}$ which serve as essential carbon nucleophiles, endowed with appealing features such as excellent functional group compatibility and high practicality, for undergoing various carbon-carbon and carbon-heteroatom bond-forming reactions, search for effective and reliable borylation reactions has continued to be an important subject in chemical synthesis. ${ }^{2,3}$ In this regard, the last decade has experienced remarkable progress in borylation reactions especially with copper catalysis, ${ }^{3-5}$ where borylcopper species generated by $\sigma$-bond metathesis with diborons have been the mainstay; their versatility has sufficiently been demonstrated by a variety of borylative addition and substitution reactions (Figure 1A). Of particular interest are three-component borylation reactions with alkynes, which provide convenient and direct access to alkenylboron compounds of structural diversity through capturing intermediary vicboryl-substituted alkenylcopper species with suitable electrophiles (Figure 1B). ${ }^{6-14}$ Since the addition of borylcopper species across alkynes (borylcupration) generally proceeds in a syn stereoselective fashion, and moreover the stereoretentive capture of boryl-substituted alkenylcopper species basically occurs with electrophiles, the most fundamental issue in the copper-catalyzed borylations of alkynes for synthesizing finely stereodefined alkenylboron compounds would be regioselectivity in the borylcupration step. 


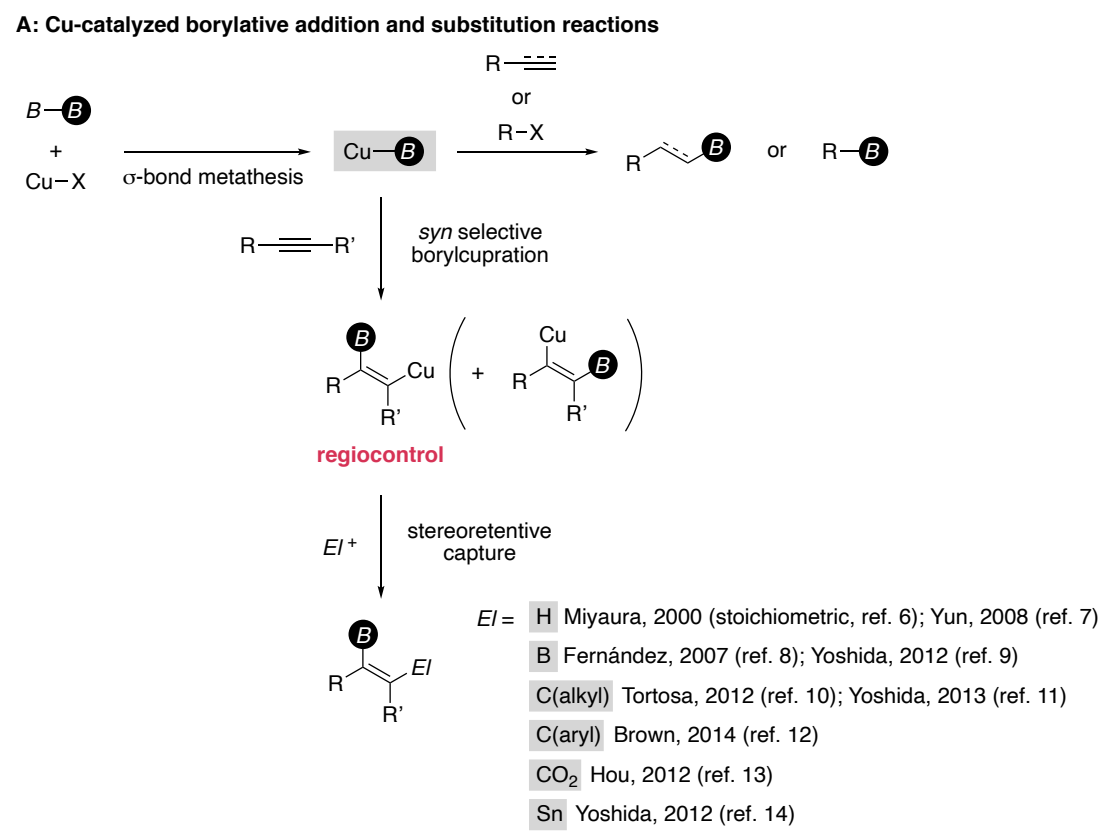

B: Cu-catalyzed three-component borylation reactions of alkynes

Figure 1. Cu-catalyzed borylation reactions with diborons

(A) Cu-catalyzed borylative addition and substitution reactions.

(B) Cu-catalyzed three-component borylation of alkynes, El, electrophile.

Internal/terminal selectivity with terminal alkynes is the typical instance of the regioselectivity, in which a boron functionality is installed into a more/less substituted carbon to give branched or linear alkenylboron compounds, respectively. The addition of the most frequently used pinacolborylcopper species [Cu-B(pin)], ${ }^{15}$ formed from (pin)B-B(pin), tend to occur with terminal selectivity (Figure 2), 7,10,13,14,16${ }^{25}$ being quite similar to that observed in the conventional borylation reactions including hydroboration (anti-Markovnikov selectivity), ${ }^{26-28}$ haloboration, ${ }^{29}$ etc., where a Lewis acidic boron center is attached to a less substituted carbon via preferential formation of a more stable alkenyl cationic transition state. These results imply that one of critical factors determining the terminal selectivity in the borylcupration should also be the inherent boron-Lewis acidity, and hence development of internal-selective borylcupration of terminal alkynes, which opens up a potent approach to underexplored copper-catalyzed borylation reactions, has been a challenging issue. In such circumstances, pioneering works on copper-catalyzed Markovnikov selective hydroboration with (pin)B-B(pin) were reported by Hoveyda (2011) $)^{30}$ and Carretero (2013), ${ }^{31}$ where terminal alkynes having a heteroatom functionality at the propargylic position efficiently accepted the internal-selective borylcupration with an $\mathrm{N}$-arylsubstituted $\mathrm{NHC}$ or $\mathrm{t}-\mathrm{Bu}_{3} \mathrm{P}$ as a ligand (Figure $3 \mathrm{~A}$ ). Although electron-deficient and neutral aryl alkynes were also found to be smoothly convertible into branched alkenylboron compounds by the copper-catalyzed hydroboration with the Hoveyda's system or with an NHC-capped cyclodextrin ligand (Roland and Sollogoub, 2017) 32 (Figure 3A), the use of electron-rich aryl alkynes and aliphatic alkynes without the electronic bias exerted by the propargylic heteroatom in these methods resulted in significantly poor regiocontrol (Figure 3B), which clearly shows the difficulty in achieving the universal internal-selective borylcupration with commonly used (pin)B$B$ (pin). On the other hand, we have disclosed that the universal internal-selective borylcupration became feasible by employing an unsymmetrical diboron, (pin)B$\mathrm{B}($ dan $)($ dan $=$ naphthalene-1,8-diaminato $),{ }^{33}$ in which the $\mathrm{B}($ dan $)$ moiety was 
exclusively attachable to an internal carbon, irrespective of electronic and steric factors of a substituent on terminal alkynes (Figure 4). ${ }^{34,35}$ Considering that the Lewis acidity of the $B($ dan) moiety is strongly diminished as compared with that of the $B$ (pin) moiety, ${ }^{36}$ the successful internal selectivity may be ascribable to the boron-Lewis acidity diminishment, however validity of this assumption remains to be fully investigated. In addition, from a standpoint of boron-based synthetic transformations, the drawback of using the Lewis acidity-diminished $\mathrm{B}(\mathrm{dan})$ is that the C(alkenyl)$\mathrm{B}(\mathrm{dan})$ bonds are directly unusable for alkenyl-carbon (or heteroatom) bond-forming reactions such as the Suzuki-Miyaura coupling (SMC) under standard conditions, thus needing prior deprotection of the dan moiety. ${ }^{37-39}$ Herein we report on origins of the internal-selective borylcupration based upon systematic investigations with some boron groups of modified Lewis acidity, leading to an effective solution to a dilemma between the internal selectivity and the activity toward direct SMC by use of a B(aam) group (aam $=$ anthranilamidato). ${ }^{40}$

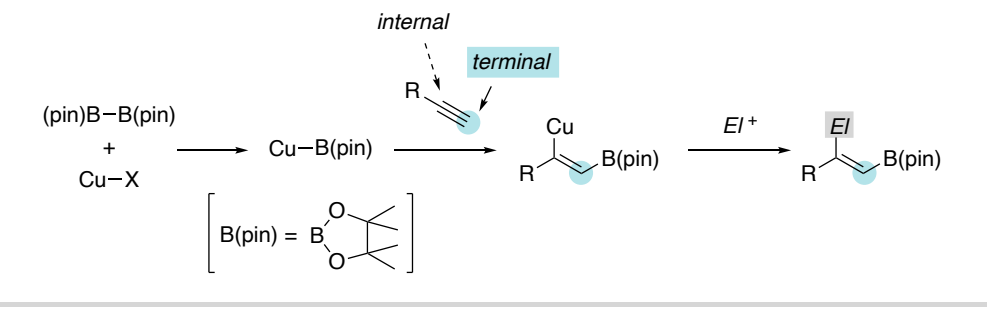

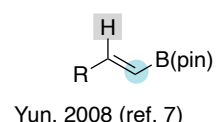

Yun, 2008 (ref. 7)

$\mathrm{Li}, 2014,2020$ (ref. 17, 18)

Nishikata, 2017 (ref. 19)

$$
\text { (spin) }
$$

Hou, 2012 (ref. 13)

Fu, 2019, 2020 (ref. 23, 24)

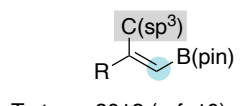

Tortosa, 2012 (ref. 10)

Zhong, 2015 (ref. 20)

Wang, 2017 (ref. 21)

Fañanás-Mastral, 2018 (ref. 22)

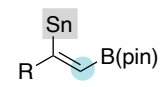

Yoshida, 2012, 2017 (ref. 14, 25)

Figure 2. Cu-catalyzed terminal-selective borylation reactions of terminal alkynes with (pin)B-B(pin) 


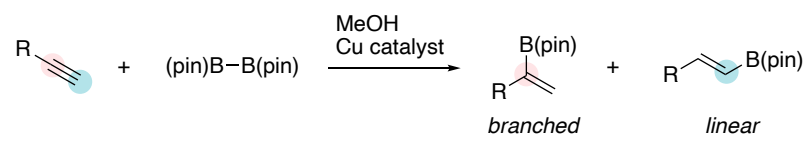

Method A: SIMesCuCl or SIPrCuCl (5 mol \%), $t$-BuONa (5 mol \%), THF; Hoveyda, 2011 (ref. 30)

$B: \mathrm{CuCl}(10 \mathrm{~mol} \%), t-\mathrm{Bu}_{3} \mathrm{P}(12 \mathrm{~mol} \%), t-\mathrm{BuONa}(15 \mathrm{~mol} \%)$, toluene; Carretero, 2013 (ref. 31)

$C$ : $\beta$-cyclodextrin-dreived NHCCuCl (5 mol \%), $t$-BuOK (40 mol \%), THF; Sollogoub, 2017 (ref. 32)

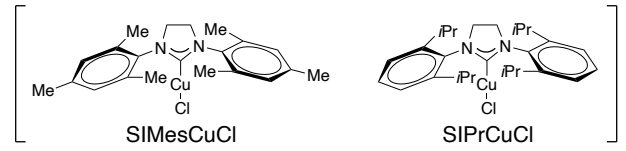

A: Internal-selective hydroboration

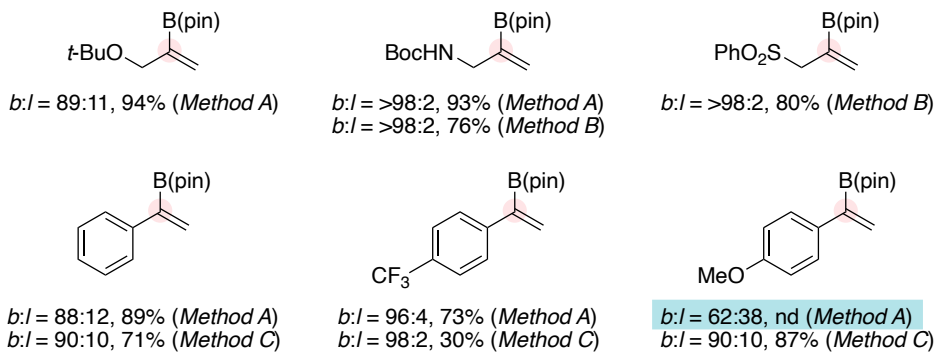

B: Terminal-selective hydroboration

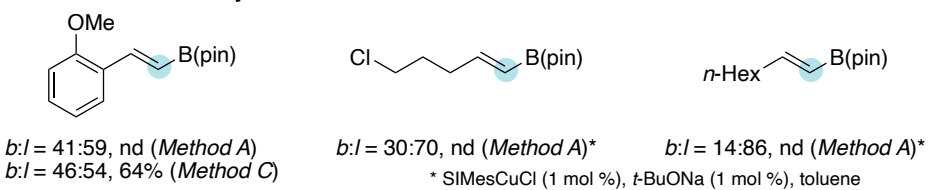

Figure 3. Regioselectivities in Cu-catalyzed hydroboration of terminal alkynes with (pin)B-B(pin)

(A) Internal-selective hydroboration.

(B) Terminal-selective hydroboration.
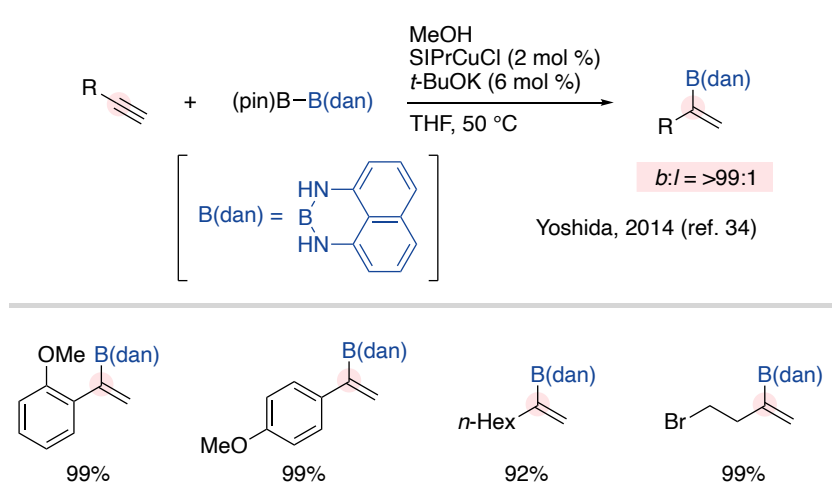

Figure 4. Cu-catalyzed internal-selective hydroboration of terminal alkynes with (pin)B-B(dan)

\section{RESULTS AND DISCUSSION}

We initially carried out the reaction of an electronically unbiased aliphatic alkyne, 1octyne (1a), with diborons of varied Lewis acidity and methanol using $\mathrm{SIPrCuCl}$ as a catalyst (Figure 5); the use of (pin)B-B(pin) (2a) resulted in the terminal-selective installation of the Lewis acidic B(pin) moiety, as was the case with the Hoveyda's system, ${ }^{30}$ giving a linear alkenylboron compound (3'aa) preferentially (branched:linear 
$=12: 88,62 \%)$. In stark contrast, the copper-catalyzed hydroboration with Lewis acidity-diminished $\mathrm{B}\left(\right.$ dan) $\left[(\text { pin)B-B(dan) (2b)] or B(aam) [(pin)B-B(aam) (2c) }]^{41}\right.$ proceeded with internal-selectivity to afford $3 a b(b: I=>99: 1,92 \%)^{34}$ or $3 a c(b: I=89: 11$, 91\%), which strongly implies that the boron-Lewis acidity diminshment is the key to achieving the internal-selectivity. Furthermore, it should be noted that the regioselectivity of the borylcupration correlates closely with the degree of the diminishment, which can be qualitatively determined by theoretical calculation-based FIA (Fluoride Ion Affinity). ${ }^{42,43}$ The calculated FIA, by means of $\mathrm{Ph}-\mathrm{BX}_{2}$ as model compounds, showed somewhat increased Lewis acidity of the $\mathrm{B}(\mathrm{aam})$ moiety (FIA = $236 \mathrm{~kJ} / \mathrm{mol}$ ), bearing a less donative amide substituent, in comparison to the $\mathrm{B}$ (dan) moiety $(F I A=216 \mathrm{~kJ} / \mathrm{mol})$, which is in good accordance with its higher hydrolyzablity, ${ }^{40,44}$ and the results clearly demonstrates that the stronger boron-Lewis acidity $[\mathrm{B}($ pin) $\gg \mathrm{B}($ aam $)>\mathrm{B}($ dan $)]$ is, the lower internal-selectivity becomes. This regiochemical tendency was further confirmed by the reaction of a new diboron [(pin)B-B(mdan) (2d), mdan = N, $N^{\prime}$-dimethyl-naphthalene-1,8-diaminato], in which the $\mathrm{B}$ (mdan) moiety of sufficiently diminished Lewis acidity $(\mathrm{FIA}=229 \mathrm{~kJ} / \mathrm{mol}$ ) provided 3ad (b:I = >99:1, 64\%) with perfect internal-selectivity. Despite its widely accepted Lewis acidic character of the $B$ (pin) moiety as is evident from the chemoselectivity in the $\sigma$-bond metathesis between (pin)B-B(dan/aam/mdan) and a $\mathrm{Cu}-\mathrm{X}$ (see Figure 9A below), and from the significantly higher reactivitity in SMC (transmetalation), ${ }^{33,36}$ sterically encumbered complexation of a fluoride ion and $\mathrm{Ph}-\mathrm{B}(\mathrm{pin})$ resulted in the decreased FIA (197 kJ/mol), which may lead to underestimation of the real B(pin)Lewis acidity. ${ }^{45,46}$

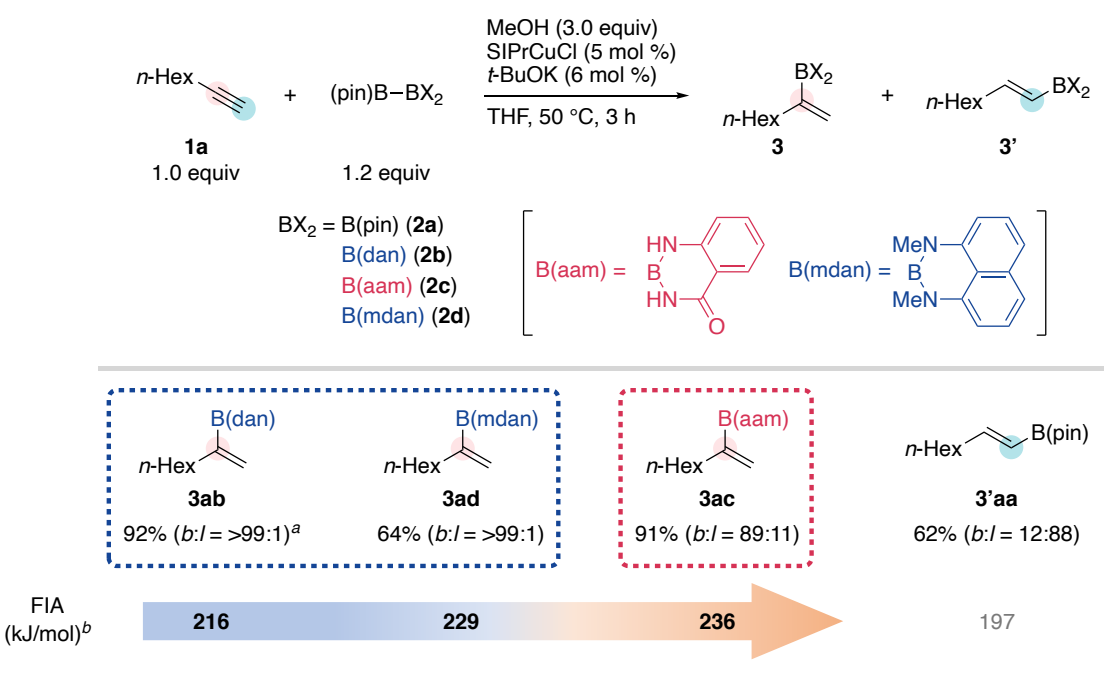

Figure 5. Regioselectivities in Cu-catalyzed hydroboration of 1-octyne with diborons of varied Lewis acidity

Standard conditions: 1-octyne 1a (1.0 equiv), diboron 2 (1.2 equiv), $\mathrm{MeOH}$ (3.0 equiv), $\mathrm{SIPrCuCl}(5 \mathrm{~mol} \%), t$-BuOK (6 mol \%), THF $(0.5 \mathrm{~mL}), 50{ }^{\circ} \mathrm{C}, 3 \mathrm{~h}$; NMR yield; regioisomeric ratios (b:l) were determined by ${ }^{1} \mathrm{H}$ NMR spectroscopy of the crude reaction mixture; only the major regioisomer was drawn.

a $\mathrm{SIPrCuCl}$ (2 mol \%); Isolated yield.

${ }^{b}$ DFT calculations were carried out at the B3LYP/6-31+G(d,p) level.

In addition to the boron-Lewis acidity, steric properties of a ligand on a copper center turned out to affect the regioselectivity significantly (Figure 6); treatment of $1 \mathrm{a}$ and $2 \mathrm{c}$ in an optimum solvent (1,4-dioxane) by employing sterically less hindered $\mathrm{IMesCuCl}$ $\left(\% V_{\text {bur }}=38.1\right)^{47}$ led to the formation of $3^{\prime}$ ac as the major product $(b: I=40: 60,42 \%)$, whereas the reaction with $\mathrm{IPrCuCl}\left(\% V_{\text {bur }}=48.5\right)$ took place with similar internal- 
selectivity (b:I $=88: 12,84 \%)$ to that with sterically comparable $\mathrm{SIPrCuCl}\left(\% V_{\text {bur }}=50.1\right.$, $b: I=91: 9,92 \%)$. Finally, perfect internal-selectivity in the B(aam)-installing hydroboration was achieved with sterically more hindered six-membered 6DippCuCl $\left(\% V_{\text {bur }}=53.4\right)$ to give $3 a c$ in $96 \%$ yield. These results obtained by the use of various diborons and ligands clearly show that key factors governing the internal regioselectivity in the borylcupration of terminal alkynes are the diminishment of boron-Lewis acidity and the ligand-derived steric bulk around a copper center. Although the reaction with sterically less bulky $\mathrm{Cl}$-substituted $\operatorname{IPr}\left(\% V_{\text {bur }}=47.1\right)$ also led to the sole formation of $3 a c$ in a lower yield, ligand electronic effects on the regioselectivity remain to be elusidated.

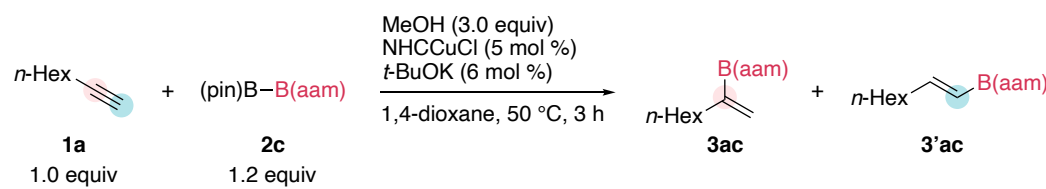

\begin{tabular}{lccc}
$\mathrm{NHCCuCl}$ & $\% V_{\text {bur }}$ & NMR yield $(\%)$ & $b: I$ \\
\hline IMesCuCl & 38.1 & 42 & $40: 60$ \\
IPrCuCl & 48.5 & 84 & $88: 12$ \\
SIPrCuCl & 50.1 & 92 & $91: 9$ \\
$6 \mathrm{DippCuCl}$ & 53.4 & 96 & $>99: 1$ \\
ClIPrCuCl & 47.1 & 77 & $>99: 1$
\end{tabular}

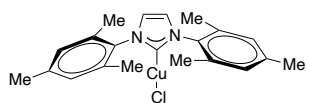

IMesCuCl

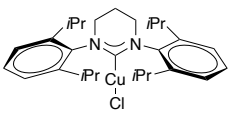

6DippCuCl

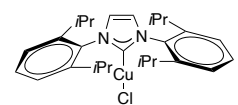

IPrCuCl

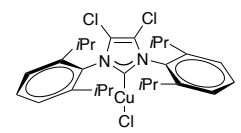

${ }^{\mathrm{Cl}} \mathrm{PrCuCl}$

Figure 6. Regioselectivities in Cu-catalyzed hydroboration of 1-octyne with (pin)B-B(aam) by use of various NHC ligands

The exclusive attachment of a boron functionality to an internal carbon of terminal alkynes with the $B(a a m)$ would be of high synthetic value, since its slightly residual Lewis acidity enables the resulting branched alkenyl-B(aam) to be directly utilized for $\mathrm{SMC}$ under standard conditions with a weak base $\left(\mathrm{K}_{3} \mathrm{PO}_{4}\right),{ }^{48}$ being in marked contrast to the cases with the $\mathrm{B}(\mathrm{dan})$ that needs acidic deprotection ${ }^{36,37,49}$ or activation by strongly basic $t$-BuOK. ${ }^{38,39}$ Thus, with the optimized reaction conditions using $6 \mathrm{DippCuCl}$, the substrate scope of the internal-selective hydroboration was investigated (Figure 7). A variety of electronically unbiased aliphatic alkynes including 1-hexyne (1b), 1-docecyne (1c), 4-methyl-1-pentyne (1d), and cyclopentylacetylene (1e) were smoothly convertible into the respective branched alkenyl-B(aam) (3bc-3ec) with perfect internal-selectivity, and a high yield of gem-boryl(silyl)ethene ( $\mathbf{3 f c}$ ) was produced from trimethylsilylacetylene (1f). In contrast to the previous B(pin)-installing hydroboration, which required a heteroatom functionality at a propargylic position for the internal-selectivity, ${ }^{30,31}$ the present method universally allowed more remote position-functionalized terminal alkynes $(\mathbf{1} \mathbf{g}-\mathbf{1 k})$ to accept the B(aam)-installation solely at their internal carbon with demonstrating the high functional group compatibility. Besides the successful transformation of phenylacetylene (1I) or 4bromophenylacetylene (1m), it is noteworthy that even $\mathrm{MeO}$-substituted electron-rich 
aryl alkynes (1 $\mathbf{n}$ and 10$)$, which only gave a mixture of isomers with poor regiocontrol under the $\mathrm{B}$ (pin)-installing conditions, ${ }^{30,32}$ underwent the internal-selective hydroboration to afford 3 nc and 3 oc in $\geqq 95 \%$ regioselectivity.

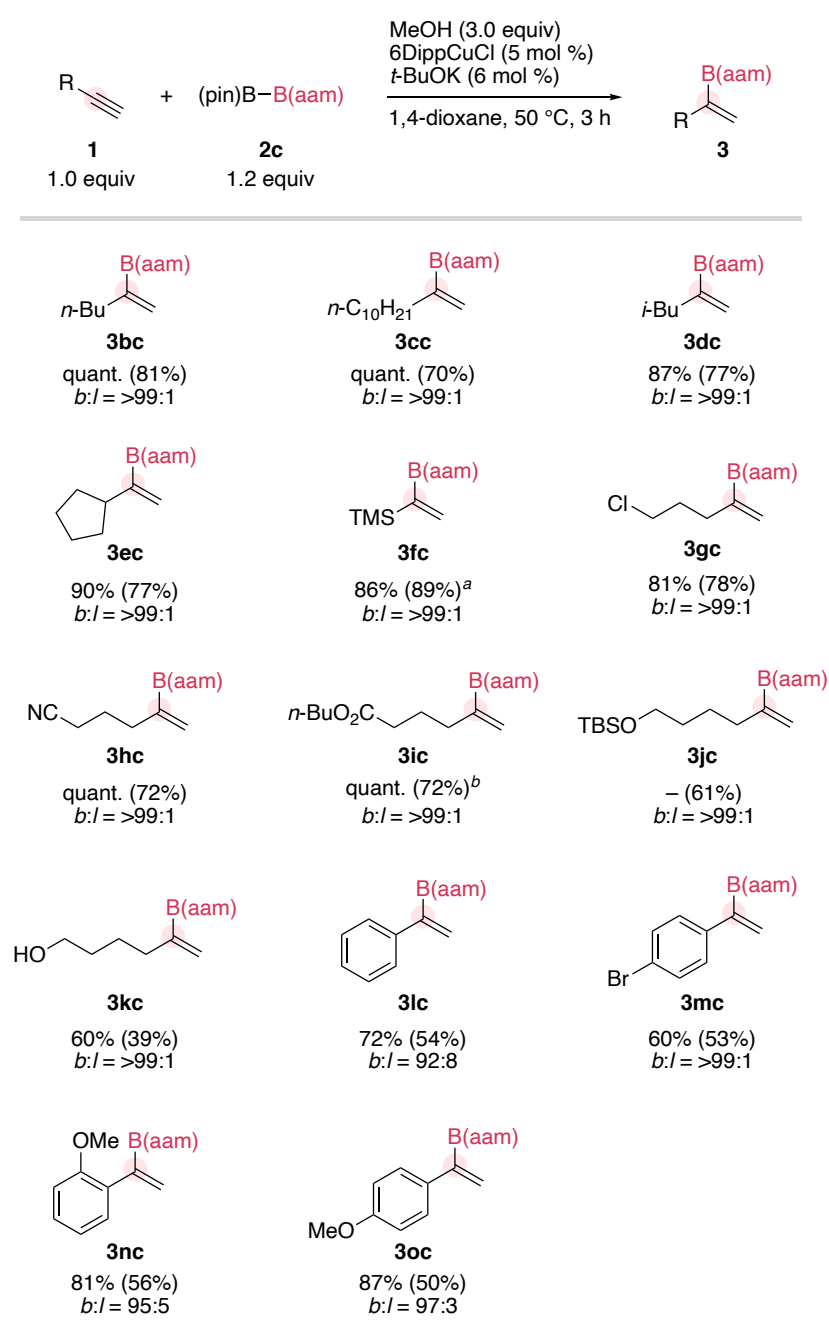

Figure 7. Cu-catalyzed internal-selective hydroboration of various terminal alkynes with (pin)B-B(aam)

Standard conditions: terminal alkyne 1 (1.0 equiv), (pin)-B(aam) 2c (1.2 equiv), $\mathrm{MeOH}$ (3.0 equiv), 6DippCuCl (5 mol \%), t-BuOK (6 mol \%), 1,4-dioxane $(0.5 \mathrm{~mL}), 50{ }^{\circ} \mathrm{C}, 3 \mathrm{~h}$; NMR yield (Isolated yield); regioisomeric ratios (b:l) were determined by ${ }^{1} \mathrm{H}$ NMR spectroscopy of the crude reaction mixture; only the major regioisomer was drawn.

a24 h.

${ }^{b} \mathrm{n}-\mathrm{BuOH}$ was used instead of $\mathrm{MeOH}$.

Synthetic versatility of the present borylation was further enhanced by a combination of direct SMC at generated alkenyl-B(aam) bonds conducted in one-pot (Figure 8); gem-boryl(silyl)ethene ( $\mathbf{3} \mathbf{f c}$ ) produced from $\mathbf{1} \mathbf{f}$ and $\mathbf{2} \mathbf{c}$ underwent sequential SMC with 4-bromobiphenyl without isolation to provide aryl(silyl)ethene (4a) in total $51 \%$ yield. Moreover, a two-step total synthesis of iso-Combretastatin A4 (4b), a highly promising cytotoxic and antitubulin agent, ${ }^{50,51}$ was also achieved depending upon the procedure by using 3,4,5-trimethoxyphenylacetylene (1p) and 3-HO-4-MeO-bromobenzene. 


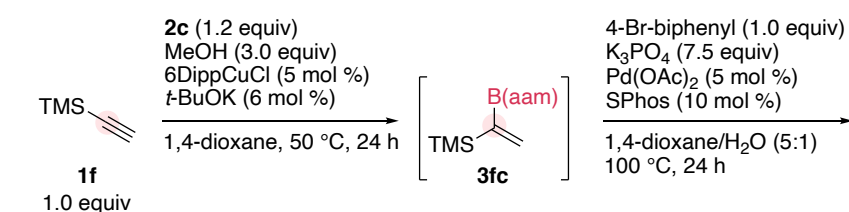

1.0 equiv

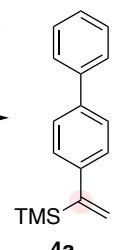

$1 \%$ total yield
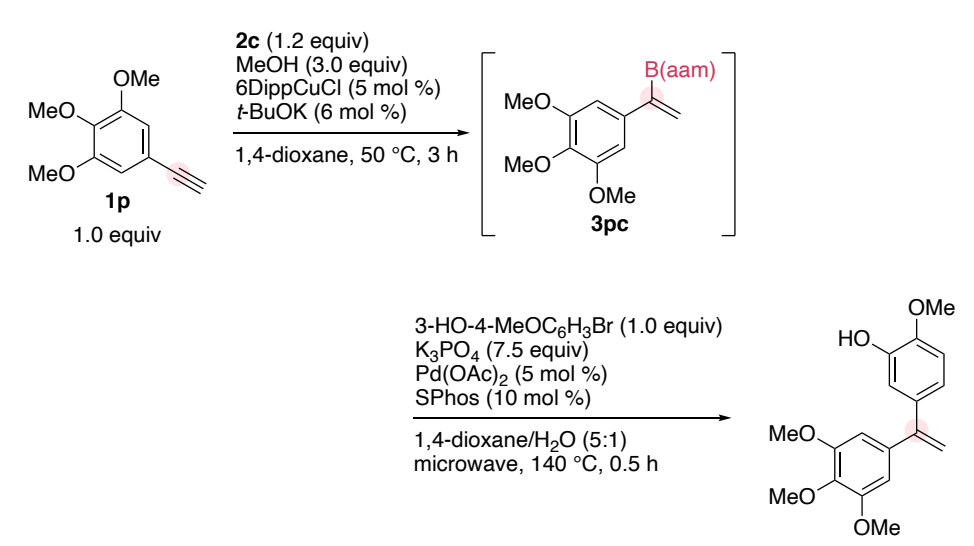

iso-Combretastatin A4 (4b)

$72 \%$ total yield

Figure 8. One pot sequential internal-selective hydroboration-Suzuki-Miyaura cross-coupling

A catalytic cycle of the $\mathrm{B}(\mathrm{aam})$-installing hydroboration would be similar to that of the well-established hydroboration with (pin)B-B(pin) (2a), ${ }^{3-5}$ and thus chemoselective formation of a $\mathrm{Cu}-\mathrm{B}(\mathrm{aam})$ species (5), which obviously implies that the $\mathrm{B}$ (pin) moiety of $\mathbf{2 c}$ is more Lewis acidic, triggers the reaction (Figure 9A). On the other hand, the $\mathrm{NH}$ moieties of the $\mathrm{B}(\mathrm{aam})$ were found to serve as a proton source for capturing an alkenylcopper intermediate (6) by the result that 3ac was produced even in the absence of $\mathrm{MeOH}$ under highly dehydrated conditions (the water content of 1,4dioxane was determined to be $5 \times 10^{-4}$ wt\% by Karl Fischer titration) (Figure 9B). In addition, the reactions with methanol-d (MeOD) offered further insights into the reaction pathway; treatment of $1 \mathbf{d}$ with $\mathbf{2 c}$ in the presence of MeOD resulted in deuterium-incorporation into both of the alkenyl- $\mathrm{H}_{\text {cis/trans }}$ moieties as well as into the $\mathrm{N}-\mathrm{H}$ moieties (Figure 9C). Among these, the $\mathrm{N}-\mathrm{H}$ moieties proved to be readily exchangeable for $\mathrm{N}-\mathrm{D}$ by the reaction of isolated 3dc with MeOD under the copper catalysis, while the alkenyl- $\mathrm{H}_{\text {cis/trans }}$ moieties totally remained unchanged (Figure 9D). These results in conjunction with copper-catalyzed smooth $\mathrm{H}-\mathrm{D}$ exchange at the alkynyl-H of 1c (Figure 9E) illustrate that the alkenyl- $D_{\text {trans }}$ of $3 \mathbf{d c}-d_{4}$ would derive from in situ-generated 4-methyl-1-pentyne-d (1d-d). 


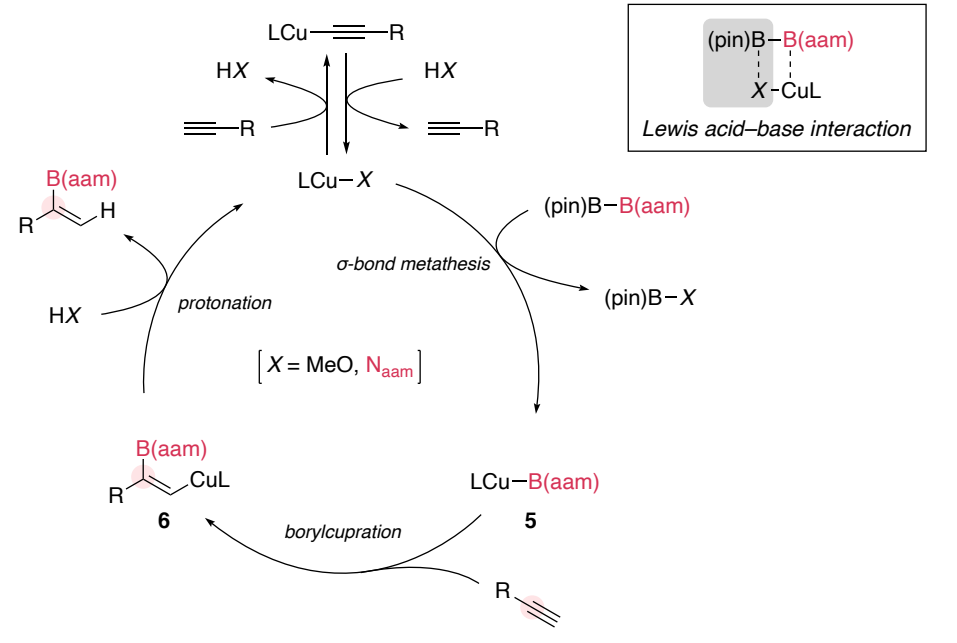

B: Hydroboration in the absence of $\mathrm{MeOH}$

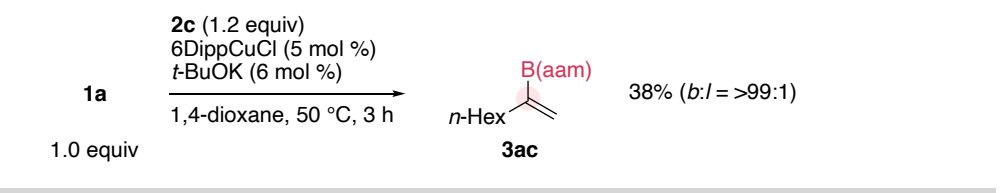

C: Hydroboration in the presence of MeOD

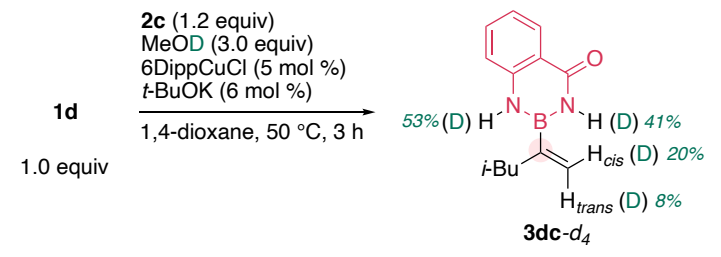

D: Treatment of 3dc with MeOD

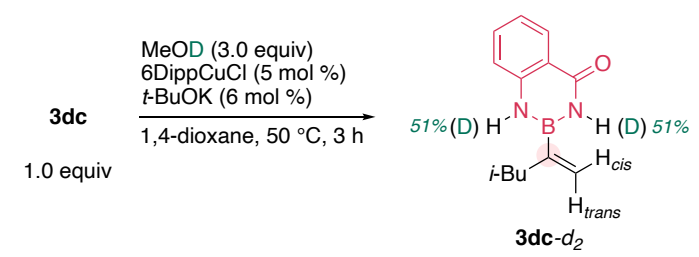

E: Treatment of 1c with MeOD

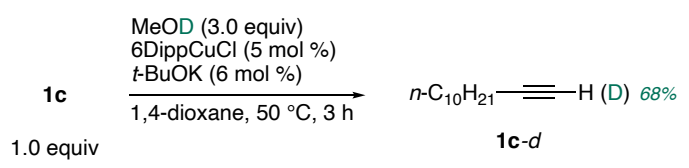

Figure 9. Mechanistic studies on a catalytic cycle

(A) Plausible catalytic cycle.

(B) Hydroboration in the absence of $\mathrm{MeOH}$.

(C) Hydroboration in the presence of MeOD.

(D) Treatment of hydroboration product 3dc with MeOD.

(E) Treatment of terminal alkyne 1c with MeOD.

\section{Conclusions}


We have disclosed that the key factors governing internal-selective borylcupration of terminal alkynes are diminishment of boron-Lewis acidity and ligand (NHC)-derived steric bulk around a copper center. The system provides us a universal way of transforming diverse terminal alkynes, irrespective of substituent nature, into branched alkenylboron compounds catalytically with almost perfect regiocontrol, which cannot be accomplished by a commonly used B(pin) moiety. The characteristic feature of the $\mathrm{B}(\mathrm{aam})$ moiety to be installed is slightly residual Lewis acidity that allows its direct use for SMC under standard conditions, and thus this was applied to the two-step total synthesis of biologically active iso-Combretastatin A4 conducted all in one-pot. In view of versatility of the boryl-substituted alkenylcopper intermediate, which can be captured by various electrophiles, the present results would open new avenues for catalytic borylations with rare regioselectivity.

\section{EXPERIMENTAL PROCEDURES}

Resource availability

Lead contact

Further information and requests for resources should be directed to and will be fulfilled by the lead contact, Hiroto Yoshida (yhiroto@hiroshima-u.ac.jp).

Materials availability

This study did not generate new unique reagents.

Data and code availability

Crystallographic data have been deposited at the Cambridge Crystallographic Data Center (CCDC) under reference numbers CCDC: 2085995 and 2085996. These data can be obtained free of charge from CCDC at http://www.ccdc.cam.ac.uk/data_request/cif.

Full experimental procedures are provided in the Supplemental information.

\section{SUPPLEMENTAL INFORMATION}

Supplemental information can be found online at

\section{ACKNOWLEDGMENTS}

This work was supported by Tonen General Sekiyu Research/Development Encouragement \& Scholarship Foundation, Hiroshima University NOZOMI H Fund Grant for the Promotion of Cancer Research, and Fukuoka Naohiko Memorial Foundation. H.T. acknowledges JSPS fellowship for young scientists, JSPS KAKENHI Grant Number JP20J22816.

\section{AUTHOR CONTRIBUTIONS}

T.T. and H.Y. designed and analyzed all experiments. T.T. performed all experiments. H.T. conducted DFT calculations. K.N. conducted X-ray crystallographic analysis. M.N. provided advice for DFT calculations. H.Y. wrote the manuscript.

\section{DECLARATION OF INTERESTS}

The authors declare no competing interests.

\section{REFERENCES}

1. E. Fernández, ed. (2020). Science of Synthesis Reference Library: Advances in
Organoboron Chemistry toward

Organic Synthesis (Thieme).
2. Neeve, E. C., Geier, S. J., Mkhalid, I. A. I., Westcott, S. A., Marder, T. B. (2016). Diboron(4) 
compounds: from structural curiosity to synthetic workhorse. Chem. Rev. 116, 9091-9161.

3. Yoshida, H. (2016). Borylation of alkynes under base/coinage metal catalysis: some recent developments. ACS Catal. 6, 1799-1811.

4. Semba, K., Fujihara, T., Terao, J., Tsuji, Y. (2015). Coppercatalyzed borylative transformations of non-polar carbon-carbon unsaturated compounds employing borylcopper as an active catalyst species. Tetrahedron 71, 2183 2197.

5. Hemming, D., Fritzemeier, R., Westcott, S. A., Santos, W. L., Steel, P. G. (2018). Copper-boryl mediated organic synthesis. Chem. Soc. Rev. 47, 7477-7494.

6. Takahashi, K., Ishiyama, T., Miyaura, N. (2000). Addition and coupling reactions of bis(pinacolato)diboron mediated by $\mathrm{CuCl}$ in the presence of potassium acetate. Chem. Lett. 982-983.

7. Lee, J.-E., Kwon, J., Yun, J. (2008). Copper-catalyzed addition of diboron regents to $\alpha, \beta$-acetylenic esters: efficient synthesis of $\beta$-boryl- $\alpha, \beta$ ethylenic esters. Chem. Commun. 733-734.

8. Lillo, V., Fructos, M. R., Ramírez, J., Braga, A. A. C., Maseras, F., Díaz-Requejo, M. M., Pérez, P. J., Fernández, E. (2007). A valuable, inexpensive $\mathrm{Cu}^{\prime} / \mathrm{N}$ heterocyclic carbene catalyst for the selective diboration of styrene. Chem. Eur. J. 13, 26142621.

9. Yoshida, H., Kawashima, S., Takemoto, Y., Okada, K., Ohshita, J., Takaki, K. (2012). Copper-catalyzed borylation reaactions of alkynes and arynes. Angew. Chem. Int. Ed. 51, 235-238.
10. Alfaro, R., Parra, A., Alemán, J., Ruano, J. L. G., Tortosa, M. (2012). Copper(I)-catalyzed formal carboboration of alkynes: synthesis of tri- and tetrasubstituted vinylboronates. J. Am. Chem. Soc. 134, 1516515168.

11. Yoshida, H., Kageyuki, I., Takaki, K. (2013). Copper-catalyzed three-component carboboration of alkynes and alkenes. Org. Lett. 15, 952-955.

12. Zhou, Y., You, W., Smith, K. B., Brown, M. K. (2014). Coppercatalyzed cross-coupling of boronic esters with aryl iodides and application to the carboboration of alkynes and allenes. Angew. Chem. Int. Ed. 53, 3475-3479.

13. Zhang, L., Cheng, J., Carry, B., Hou, Z. (2012). Catalytic boracarboxylation of alkynes with diborane and carbon dioxide by an N-heterocyclic carbene copper catalyst. J. Am. Chem. Soc. 134, 14314-14317.

14. Takemoto, Y., Yoshida, H., Takaki, K. (2012). Coppercatalyzed three-component borylstannylation of alkynes. Chem. Eur. J. 18, 14841-14844.

15. For isolation and characterization, see: Laitar, D. S., Müller, P., Sadighi, J. P. (2005). Efficient homogeneous catalysis in the reduction of $\mathrm{CO}_{2}$ to CO. J. Am. Chem. Soc. 127, 17196-17197.

16. Tai, C.-C., Yu, M.-S., Chen, Y.-L., Chuang, W.-H., Lin, T.-H., Yap, G. P. A., Ong, T.-G. (2014). Synthesis of a guanidine NHC complex and its application in borylation reactions. Chem. Commun. 50, 4344-4346.

17. Zhao, J., Niu, Z., Fu, H., Li, Y. (2014). Ligand-free hydroboration of alkynes catalyzed by heterogenous copper powder with high efficiency. Chem. Commun. 50, 2058-2060.

18. Zhang, J., Wang, Z., Chen, W., Xiong, Y., Cheong, W.-C., Zheng, L., Yan, W., Gu, L., Wang, D., Li, Y. et al. (2020). Tuning polarity of $\mathrm{Cu}-\mathrm{O}$ bond in heterogeneous $\mathrm{Cu}$ catalyst to promote additive-free hydroboration of alkynes. Chem 6, 725-737.

19. Tanaka, C., Nakamura, K., Nishikata, T. (2017). Coppercatalyzed reductive borylations on water. Tetrahedron 73, 3999-4003.

20. Bin, H.-Y., Wei, X., Zi, J., Zuo, Y.J., Wang, T.-C., Zhong, C.-M., (2015). Substrate-controlled regio- and stereoselective synthesis of boron-substituted 1,4-dienes via copper-catalyzed boryl-allylation of alkynes with allyl phosphates and bis(pinacolato)diboron. ACS Catal. 5, 6670-6679.

21. Jing, H., Feng, X., Guo, M., Zhou, S., Li, Y., Zhang, J., Zhao, W., Tang, X., Wang, G. (2017). Copper-catalyzed regioselective formal allylboration of arylsubstituted terminal alkynes with bis(pinacolato)diboron and allyl halides/sulfonates. Asian J. Org. Chem. 6, 1375-1379.

22. Rivera-Chao, E., FañanásMastral, M. (2018). Synthesis of stereodefined borylated dendralenes through coppercatalyzed allylboration of alkynes. Angew. Chem. Int. Ed. 57, 9945-9949.

23. Li, K., Yu, S.-H., Zhuo, K.-F., Lu, X., Xiao, B., Gong, T.-J., Fu, Y. (2019). Synthesis of conjugated boron-enynes via cisalkynylboration of terminal alkynes. Adv. Synth. Catal. 361, 3937-3942.

24. Yu, S.-H., Gong, T.-J., Fu, Y. (2020). Three-component borylallenylation of alkynes: access to densely boryl- 
substituted ene-allenes. Org. Lett. 22, 2941-2945.

25. Yoshida, H., Kimura, M., Osaka, I., Takaki, K. (2017). Coppercatalyzed borylstannylation of alkynes with tin fluorides. Organometallics 36, 1345-1351.

26. Tucker, C. E., Davidson, J., Knochel, P. (1992). Mild and stereoselective hydroborations of functionalized alkynes and alkenes using pinacolborane. J. Org. Chem. 57, 3482-3485.

27. Pereira, S., Srebnik, M. (1996). A study of hydroboration of alkenes and alkynes with pinacolborane catalyzed by transition metals. Tetrahedron Lett. 37, 3283-3286.

28. Wang, Y. D., Kimball, G., Prashad, A. S., Wang, Y. (2005). Zr-mediated hydroboration: stereoselective synthesis of vinyl boronic esters. Tetrahedron Lett. 46, 8777-8780.

29. Suzuki, A. (1986). New application of organoboron compounds in organic synthesis. Pure Appl. Chem. 58, 629-638.

30. Jang, H., Zhugralin, A. R., Lee, Y., Hoveyda, A. H. (2011). Highly selective methods for synthesis of internal ( $\alpha$-) vinylboronates through efficient $\mathrm{NHC}-\mathrm{Cu}$ catalyzed hydroboration of terminal alkynes. Utility in chemical synthesis and mechanistic basis for selectivity. J. Am. Chem. Soc. 133, 78597871.

31. Moure, A. L., Mauleón, P., Arrayás, R. G., Carretero, J. C. (2013). Formal regiocontrolled hydroboration of unbiased internal alkynes via borylation/allylic alkylation of terminal alkynes. Org. Lett. 15, 2054-2057.

32. Zhang, P., Suárez, J. M., Driant, T., Derat, E., Zhang, Y., Ménand, M., Roland, S., Sollogoub, M. (2017). Cyclodextrin cavity- induced mechanistic switch in copper-catalyzed hydroboration. Angew. Chem. Int. Ed. 56, 10821-10825.

33. Iwadate, N., Suginome, M. (2010). Differentially protected diborons for regioselective diboration of alkynes: internalselective cross-coupling of 1 alkene-1,2-diboronic acid derivatives. J. Am. Chem. Soc. 132, 2548-2549.

34. Yoshida, H., Takemoto, Y., Takaki, K. (2014). A masked diboron in Cu-catalysed borylation reaction: highly regioselective formal hydroboration of alkynes for synthesis of branched alkenylborons. Chem. Commun. 50, 8299-8302.

35. Yoshida, H., Takemoto, Y., Takaki, K. (2015).

Borylstannylation of alkynes with inverse regioselectivity: coppercatalyzed three-component coupling using a masked diboron. Chem. Commun. 51, 6297-6300.

36. $A B$ (pin) moiety is much more reactive than a $B(d a n)$ moiety in transmetalation of the SuzukiMiyaura coupling, which demonstrates its stronger Lewis acidity. See: Noguchi, H., Shioda, T., Chou, C.-M., Suginome, M. (2008).

Differentially protected benzenediboronic acids: divalent cross-coupling modules for the efficient synthesis of boron-substituted oligoarenes. Org. Lett. 10, 377-380. See also ref. 33.

37. Iwadate, N., Suginome, M. (2009). Synthesis of B-protected $\beta$-styrylboronic acids via iridiumcatalyzed hydroboration of alkynes with 1,8naphthalenediaminatoborane leading to iterative synthesis of oligo(phenylenevinylene)s. Org. Lett. 11, 1899-1902.
38. For direct activation of $\mathrm{C}\left(\mathrm{sp}^{2}\right)-$ $\mathrm{B}(\mathrm{dan})$ bonds with a strong base toward SMC, see: Yoshida, H., Seki, M., Kamio, S., Tanaka, H., Li, J., Abe, M., Andoh, H., Yajima, T., Tani, T., Tsuchimoto, T. et al. (2020). Direct SuzukiMiyaura coupling with naphthalene-1,8-diaminato (dan)-substituted organoborons. ACS Catal. 10, 346-351.

39. Mutoh, Y., Yamamoto, K., Saito, S. (2020). Suzuki-Miyaura crosscoupling of 1,8diaminonaphthalene (dan)protected arylboronic acids. ACS Catal. 10, 352-357.

40. A B(aam) group was reported to be a protected boron moiety in SMC. See: Ihara, H., Koyanagi, M., Suginome, M. (2011). Anthranilamide: a simple removable ortho-directing modifier for arylboronic acids serving also as a protecting group in cross-coupling reactions. Org. Lett. 13, 26622665.

41. Kamio, S., Kageyuki, I., Osaka, I., Hatano, S., Abe, M., Yoshida, H. (2018). Anthranilamide (aam)substituted diboron: palladiumcatalyzed selective B(aam) transfer. Chem. Commun. 54, 9290-9293.

42. Böhrer, H., Trapp, N., Himmel, D., Schleep, M., Krossing, I. (2015). From unsuccessful $\mathrm{H}_{2-}$ activation with FLPs containing $\mathrm{B}$ (Ohfip) 3 to a systematic evaluation of the Lewis acidity of 33 Lewis acids based on fluoride, chloride, hydride and methyl ion affinities. Dalton Trans. 44, 7489-7499.

43. Erdmann, P., Leitner, J., Schwarz, J., Greb, L. (2020). An extensive set of accurate fluoride ion affinities for $p$-block element Lewis acids and basic design principles for strong fluoride ion acceptors. ChemPhysChem 21, 987-994. 
44. A B(pin) moiety was also reported to be much more hydrolyzable than a B(dan) moiety. See:

Manankandayalage, C. P., Unruh, D. K., Krempner, C. (2020). Boronic, diboronic and boric acid esters of 1,8naphthalenediol - synthesis, structure and formation of boronium salts. Dalton Trans. 49, 4834-4842.

45. A similar underestimation arising from the steric encumbrance of the $B$ (pin) moiety was observed in evaluation of its Lewis acidity by the Gutmann-Beckett method. See: Zukowska, G., Szczechura, M., Marcinek, M., Zubrowska, A., AdamczykWoźniak, A., Sporzyński, A., and Wieczorek, W. (2009).

Investigation on the Anion Complexation Ability of Organoboron Additives in Lithium-ion Battery Electrolytes -
Spectroscopic Approach. ECS Trans. 16, 105-114.

46. Although the computed FIA indeed provides us a powerful method for estimating boronLewis acidity, these results imply that the FIA-based comparison of boron-Lewis acidity, especially among ones without structural similarity, should carefully be conducted.

47. Nolan, P. S., Clavier, H. (2010). Percent buried volume for phosphine and N-heterocyclic carbene ligands: steric properties in organometallic chemistry reactions. Chem. Commun. 46, 841-861.

48. Kamio, S., Kageyuki, I., Osaka, I., Yoshida, H. (2019). Anthranilamide (aam)substituted arylboranes in direct carbon-carbon bond-forming reactions. Chem. Commun. 55, 2624-2627.

49. Noguchi, H., Hojo, K., Suginome, M. (2007). Boron- masking strategy for the selective synthesis of oligoarenes via iterative SuzukiMiyaura coupling. J. Am. Chem. Soc. $129,758-759$.

50. Messaoudi, S., Tréguier, B., Hamze, A., Provot, O., Peyrat, J.-F., De Losada, J. R., Liu, J.M., Bignon, J., WdzieczakBakala, J., Alami, M. et al. (2009). Isocombretastatins $A$ versus combretastatins $A$ : the forgotten isoCA-4 isomer as a highly promising cytotoxic and antitubulin agent. J. Med. Chem. 52, 4538-4542.

51. Hamze, A., Giraud, A., Messaoudi, S., Provot, O., Peyrat, J.-F., Bignon, J., Liu, J.M., Wdzieczak-Bakala, J., Thoret, S., Alami, M. et al. (2009). Synthesis, biological evaluation of 1,1-diarylethylenes as a novel class of antimitotic agents. ChemMedChem 4, 1912-1924. 